\title{
nature
}

21 February 2002 Volume 415 Issue no 6874

\section{Thoughts on (dis)credits}

A Commentary by Peter Lawrence on page 835 condemns the hogging of credit by "big names". Reactions and anecdotes from editors and from external advisers in response to this article speak for themselves.

“| once was in a conversation between a PI [principal investigator] and his postdoc, when the PI started to complain that he wasn't on the author list of the postdoc's latest paper. The postdoc boldly replied that he considered that to be on the paper, someone would have to have contributed, either a figure or a piece of text, or a basic idea. As the PI hadn't, he wasn't on it. The PI had to agree (and they still work together). I guess the lesson from that is that perhaps sometimes postdocs need to speak up and fight for their right (and each other's rights!) as well. For example, always put your name on transparencies you 'lend' to your PI. They might really just forget if it's not there - even PIs are sometimes nervous when they talk."

"There are bad apples in the scientific community, to be sure. And there are poor mentors, and serial abusers of younger scientists for the advancement of the careers of 'The Great Leader'. I have seen some of these people in action at close range. Yet the majority of scientists and mentors are not like that - so my fear is that the majority could be tarred by the sins of the minority. Moreover, there's nothing inherently wrong with running a moderate-sized laboratory, nor with taking an appropriate degree of credit for the work in one's lab. The PI has to do an enormous amount of work to bring in the funds, provide the research facilities, ensure everything is conducted legally (increasingly difficult to do), and guide the project. Done right, as it usually is, both the PI and the more junior scientist benefit. So I don't see anything much wrong with the system, only with the way a minority of scientists exploit some aspects of it."

"As is acknowledged, it is often the person who had the idea to try something who should be credited, and not only the one who went ahead and did it. So I think quite often, PIs should be given credit - it's not by chance that some labs are productive and others aren't, and I don't think it's just clever selection of the best students, either."

"I wrote a meeting report and cited a poster. It was presented by the second author, whom I credited, which resulted in an e-mail from the first author (a postdoc — but I didn't know that at the time), saying that she just hadn't had the funding to go to the conference. We published a correction, but I don't think that's quite as good. So the lesson is that this is easily done, without meaning any harm, and that we all should be vigilant."

"A referee of a paper submitted by Professor X, a big shot, asked that X do some further experiments. X's response was: 'The statement that I have done all the experiments is quite insulting to the colleague who actually did the work. I have not done any experiment. The reviewer should take these facts more seriously and earnestly as a comrade and citizen in the scientific community."”
"There are ways out of this. An excellent innovation are schemes by, for example, the Royal Society giving promising young researchers long fellowships and a good measure of independence. For example, Y was one of the many people who was working on [...] when they became big news in the 1980s. Realizing that the world would be full of people working on [...], he used his independence to do two things. First, he worked on [...] in long-neglected animals, revitalizing a whole area of research; and second, he published in all kinds of obscure journals, 'just because they were there. This insouciance combined with the novelty of his approach landed $\mathrm{Y}$ a full professorship at the age of 31. If postdocs were funded in an independent way, not tied to a PI, they could stick up two fingers if they felt that credit was being stolen."

"The sociology of authorship varies according to the scientific discipline. Some mathematical journals still expect alphabetical listing. My epidemiological collaborators recently sent me a draft manuscript where my name comes last. I enquired why I was privileged to be placed in the 'senior' position. Their puzzled response was that the authorship was, as a matter of course, listed according to the importance of the contribution, but they were pleased I wasn't offended to be last!"

From Nature's Guide to Authors and cited editorial:

"Authors are encouraged to specify the contribution made by their co-authors in the Acknowledgements (see Nature 399, 393; 1999)" ... "We hope that, as the practice spreads, the dishonourable practice of 'honorary authorship' - authorship by virtue only of seniority, for example — will diminish.”

A letter, unedited, submitted in January for publication by the late Max Perutz (see Obituary, page 851):

"Much of Peter Lawrence's Commentary shocked me, even though I had received reports of such goings-on from many sources. It used not to be like that. I spent the first 25 years of my scientific life in the Cavendish laboratory, Cambridge, which was then headed by Ernest Rutherford, one of the greatest experimental physicists of all time and, after that, by W. L. Bragg, the pioneer of X-ray crystallography.

"Neither ever put their names to papers to which they themselves had not contributed. Rutherford did not sign his name on two of the greatest discoveries of the Cavendish: Cockcroft and Walton's first artificial atomic disintegration and Chadwick's discovery of the neutron. During the 15 years of our collaboration, Bragg never signed any paper of mine to which he had not contributed. In our joint papers, his contribution was normally the major one. I have tried to follow their example throughout my scientific life. I did not sign Giulio Fermi's paper on the structure of human deoxyhaemoglobin, Boaz Shaanan's on oxyhaemoglobin, Simon Phillips' on the stereochemistry of the iron-oxygen bond in myoglobin, nor Ben Luisi's on the allosteric binding site — all key papers. I had my reward in their lasting respect and affection, and it did not damage my scientific career." 5 